\title{
ROLE OF DIAGNOSTIC LAPAROHYSTEROSCOPY IN THE MANAGEMENT OF INFERTILE FEMALES.
}

Richa Singh, Saroj Singh, Poonam Yadav, Meenakshee Goyal

1. Associate Professor. Department of Obstetrics \& Gynecology, S. N. Medical College, Agra,

2. Professor. Department of Obstetrics \& Gynecology, S. N. Medical College, Agra,

3. Assistant Professor. Department of Obstetrics \& Gynecology, S. N. Medical College, Agra,

4. Junior Resident. Department of Obstetrics \& Gynecology, S. N. Medical College, Agra,

\section{CORRESPONDING AUTHOR:}

Dr. Richa Singh,

Associate Proffesor,

1/120-G, Delhi Gate, Agra-282002.

E-mail: chauhan.richavishal@gmail.com

ABSTRACT: AIMS: To evaluate the role of diagnostic laparohysteroscopy in the management of infertile females. SETTINGS AND DESIGN: The study was conducted in the department of obstetrics and gynaecology, S.N. Medical College, Agra. Total 100 infertile couples attending the outpatient department of obstetrics and Gynaecology were selected. 60 couples belonged to primary infertility group while 40 couples belonged to secondary infertility group. METHODS AND MATERIAL: All patients underwent transvaginal sonography with sonosalpingography. Then all patients were subjected to combined laparohysteroscopy including chromopertubation and the results were recorded. All the findings were noted on case sheet and a master chart was prepared. $\mathrm{X}^{2}$ test was applied to find out significance of tests. P value $<0.05$ was considered as significant. RESULTS: The laparoscopy was abnormal in 68\% cases: Peritoneal and peri-tubal adhesions (29\%), phimosis / hydrosalpinx (19\%), polycystic ovaries (26\%), tubo-ovarian masses (16\%), endometriosis (4\%), congenital abnormalities (10\%), myomas (3\%), bilateral tubal blockage(49\%) and unilateral tubal blockage(17\%). The operative laparoscopy was performed in 53\% of cases. The hysteroscopy was abnormal in 50\% cases : uterine synechias (11\%), thick endometrium (15\%), endometrial polyps (7\%), myomas $(2 \%)$, atrophy (6\%), congenital abnormalities $(7 \%)$ and foetal bones $(2 \%)$. The operative hysteroscopy procedure was performed in $38 \%$ cases. The pregnancy rate was $32.30 \%$. CONCLUSION: Results show that laparohysteroscopy has a promising role in diagnosing and treating infertility. Thus laparohysteroscopy has emerged as a new hope for infertile couples before they proceed to time-consuming and expensive in-vitro fertilization.

KEY WORDS: Infertility, laparoscopy, Hysteroscopy, cost-effective.

INTRODUCTION: Infertility is defined as 1 year of unprotected intercourse without pregnancy. ${ }^{1}$ The prevalence of infertility ranges from $3.5 \%$ to $16.7 \%$ in more developed nations and from $6.9 \%$ to $9.3 \%$ in less developed nations, with an estimated overall median prevalence of $9 \%{ }^{2}$

Laparoscopy is considered the gold standard for diagnosing tubal and peritoneal disease. It is transperitoneal endoscopic technique that provides direct visualization of pelvis and complete view of cul-de-sac, pelvic side walls and all pelvic viscera. Hysteroscopy is a procedure that involves insertion of an endoscope through the cervical canal into the uterine cavity and instillation of distention media to allow for visualization ${ }^{3}$. 
The present study aims to evaluate the role of combined laparohysteroscopy in the diagnosis of the probable causes of infertility and in the correction of treatable factors discovered.

MATERIAL AND METHODS: The study was conducted in the department of Obstetrics and Gynaecology in collaboration with the department of Radiodiagnosis, Sarojini Naidu Medical College, Agra during the study period (Jan 2011 to Oct 2012). A total of 100 cases presenting with complaint of infertility attending the out patient department of Obstetrics and Gynaecology were selected. 60 cases belonged to primary infertility group while 40 cases belonged to secondary infertility group.

\section{Inclusion Criteria.}

1. Married women between age group 20-40 years were selected.

2. All women were unable to conceive after atleast 12 months of regular, unprotected intercourse.

\section{Exclusion Criteria}

1. Couples with male factor abnormalities.

2. Patients with developmental defects like Turner syndrome and Mullerian agenesis.

3. Patients with hypothalamic pituitary causes.

4. Patients who have absolute or relative contraindications for laparoscopy and hysteroscopy.

The selected patients were evaluated by detailed history and thorough clinical examination. Investigations done were haemogram, blood sugar, husband seminogram, ESR, liver and kidney function tests, Mantoux test, blood hormone levels S. LH, FSH, Prolactin, Oestradiol, pap smear, chest X-Ray, transvaginal sonography with sonosalpingography. Then all the patients were subjected to laparohysteroscopy.

On hysteroscopy, uterine cavity was examined for the presence of septum, any congenital malformation, fibrotic bands, polyps, myomas, endometrial appearance, thickness and colour. Endocervical canal was visualized for any growth or polyps. Both the tubal ostia were visualized.

On laparoscopy, pelvic cavity and organs were inspected. Uterus was inspected for its shape, size, position and surface. Cul-de-sac was examined for any adhesions, obliteration, endometriotic nodules or fluid. Ovaries were viewed for size, shape, surface, colour, presence of cysts and relation with tubes. Fallopian tubes were inspected carefully for size, shape, surface, kinking, dilatation, stricture or hydrosalpinx. Laparoscopic chromopertubation was performed for testing tubal patency in which methylene blue dye is injected with a $20 \mathrm{ml}$ syringe via Leech Wilkinson cannula and spillage of dye from the fimbrial end of tube visualized.

Surgical interventions were also performed which include adhesiolysis, fimbrioplasty, tubal cannulation, Ovarian drilling, fulguration of endometriotic lesions, cyst excision, hysteroscopic polypectomy and endometrial curettage.

All the findings were noted on case sheet and a master chart was prepared. $\mathrm{X}^{2}$ test was applied to find out significance of tests. P value $<0.05$ was considered as significant. 
The patients were followed for a period of one year in which 23 patients were lost to follow up and in remaining ovulation induction and serial ultrasonography for follicular monitoring was done.

RESULTS: Most of the patients in the present study were in the age group of 26-30 years. Oligo /hypomenorrhea was the most common menstrual complaint. Transvaginal sonography identified abnormal findings in 49\% patients: most common being polycystic / multicystic ovaries (17\%) and thick endometrium (11\%).

Hysteroscopy revealed abnormal finding in $50 \%$ patients. The most common finding was thick/irregular endometrium in $15 \%$ patients followed by intra-uterine adhesions in $11 \%$ patients .Other findings were endometrial polyps(7\%), myomas(2\%) ,congenital abnormalities(7\%), atrophic endometrium/sclerotic ostia(6\%), and foetal bones embedded in endometrium(2\%).(Table-1)

On laparoscopy, we found abnormalities in 68\% patients. Peritoneal adhesions (29\%) and polycystic / multicystic ovaries (26\%) were the most common findings .Other findings were phimosis/hydrosalpinx(19\%), tubo-ovarian masses(16\%), endometriosis(4\%), functional ovarian cyst(8\%), myomas(3\%) and congenital abnormalities(10\%).(Table-2)

Interventions were performed in $38 \%$ patients by hysteroscopy which include polypectomy(7\%), adhesiolysis(8\%), tubal cannulation(6\%) and endometrial curettage(17\%).(Table-3)

Interventions were performed in $53 \%$ patients by laparoscopy which include adhesiolysis(21\%), ovarian drilling(26\%), fimbrioplasty(15\%), fulguration of endometriotic lesions(3\%), excision of ovarian endometriotic cyst(1\%) and myomectomy(3\%).(Table-4)

For testing tubal patency, there was $76.80 \%$ agreement between results of sonosalpingography and laparoscopic chromopertubation. The sensitivity of sonosalpingography for testing tubal patency was $63.71 \%$, specificity $95.06 \%$, positive predictive value $94.73 \%$ and negative predictive value $65.25 \%$ Chi. square test detected the difference to be significant $(\mathrm{p}<0.05 ?=\mathrm{x})$

All the patients in the study group were followed for a period of 1 year during which ovulation induction and serial ultrasonographic follicular study was done. 12 patients with frozen pelvis and uncorrectable bilateral tubal occlusion were referred for in-vitro fertilization. 23 patients were lost to follow up. 21 infertile couples conceived - 6 with normal findings on laparohysteroscopy, 5 with laparoscopic ovarian drilling, 4 on anti-tubercular treatment, 2 with proximal tubal cannulation, 2 with fimbrioplasty, 1 with lysis of intra-uterine adhesions followed by $\mathrm{Cu}-\mathrm{T}$ insertion and hormonal pills for endometrial development and 1 with peritoneal adhesiolysis. Pregnancy rate was $32.30 \%$. 2 of the patients who conceived had spontaneous abortion.(Table-5)

DISCUSSION: Since age being an important prognostic factor in infertility, emphasis is now on simplified, time-efficient investigative protocols that provide sufficient information to plan effective management.

In the present study of 100 patients, laparoscopic examination revealed atleast one abnormal finding in $68 \%$ patients and $50 \%$ patients had abnormal finding at hysteroscopy. 6 patients had abnormal hysteroscopic findings but normal laparoscopic 
findings. Out of 68 patients with abnormal laparoscopy 44 had abnormal findings at hysteroscopy. Hysteroscopy couldn't be done in 2 patients. Number of cases with normal findings on TVS was 51 which was reduced to 26 on evaluation by laparohysteroscopy. We applied Chi-square test to evaluate the significance of difference between the results of TVS and laparohysteroscopy and the difference was found to be significant $\left(p<0.010^{2}=\right.$ 5.6).

Hysteroscopy revealed abnormal findings in 50\% patients: Intra-uterine adhesions (11\%), atrophic endometrium / sclerotic ostia (6\%), endometrial polyps (7\%), congenital abnormalities (7\%), Irregular / thick endometrium (15\%) and normal findings (48\%).

These findings were similar to Boudhraa et $\mathrm{al}^{4}$ who reported intra-uterine adhesion (23\%), atrophic endometrium / sclerotic ostia (7.5\%), endometrial polyp (10\%), congenital abnormalities (3.5\%), Irregular / thick endometrium (19\%) and normal findings (25\%). Malhotra $\mathrm{N}$ et al.5 reported intra-uterine adhesions (25\%), atrophic endometrium (9.4\%) and congenital abnormalities (6.1\%).

Laparoscopy revealed abnormal findings in 68\% patients : Adhesions (29\%), endometriosis (4\%), phimosis / hydrosalpinx (19\%), polycystic ovaries (26\%), functional ovarian cyst (8\%), myoma (3\%), congenital abnormalities (10\%), tubo-ovarian masses $(16 \%)$ and normal findings in $32 \%$ patients.

These findings were similar to Sajida Parveen et al ${ }^{6}$ who reported adhesions (11.2\%), endometriosis (8\%), phimosis / hydrosalpinx (6\%), polycystic ovaries $(19.35 \%)$, functional ovarian cyst (4.8\%), myoma (4.83\%), congenital abnormalities (12.9\%), tuboovarian masses(8\%) and normal findings in $16.2 \%$, patients.

In our study interventions were performed in the form of adhesiolysis in $21 \%$ cases, drilling of polycystic ovaries in $26 \%$ cases fimbrioplasty in $15 \%$, fulguration or excision of endometriosis nodules in $4 \%$ and myomectomy in $3 \%$ cases.

In study by Boudhraa $\mathrm{K}$ et $\mathrm{al}^{4}$ operative laparoscopy was performed in $70 \%$ of cases divided between adhesiolysis (27.2\%), tubal surgery (37.8\%), fulguration or excision of endometriosis nodules (17.2\%) and ovarian drilling for PCOS (17.8\%).

Laparoscopic chromopertubation was found better than sonosalpingography for testing tubal patency.

Pelvic adhesions and polycystic ovaries were the most common finding in patients with infertility mainly due to high prevalence of chronic pelvic inflammatory disease and tuberculosis. The pregnancy rate in our study was $32.30 \%$. In the study by Boudhraa K et $\mathrm{al}^{4}$ the rate of pregnancy was $39.9 \%$.

CONCLUSION: It is concluded that while investigating the causes of female infertility combined simultaneous diagnostic laparoscopy and hysteroscopy should be performed in all infertile patients before treatment. Thus laparohysteroscopy has emerged as a new hope for infertile couples before they proceed to time-consuming and expensive in-vitro fertilization. 
Table-1 Distribution of cases according to hysteroscopic findings

\begin{tabular}{|l|c|c|c|c|c|}
\hline Hysteroscopic findings & $\begin{array}{c}\text { Primary } \\
\text { infertility } \\
\text { (N=60) }\end{array}$ & $\begin{array}{c}\text { Percentage } \\
\mathbf{( \% )}\end{array}$ & $\begin{array}{c}\text { Secondary } \\
\text { infertility } \\
\mathbf{( N = 4 0 )}\end{array}$ & $\begin{array}{c}\text { Percentage } \\
\mathbf{( \% )}\end{array}$ & $\begin{array}{c}\text { Total No. } \\
\text { of cases. }\end{array}$ \\
\hline Adhesions & 2 & 3.33 & 3 & 7.5 & 5 \\
\hline \multicolumn{1}{|c}{ Mild $\quad$ Moderate } & 2 & 3.33 & 2 & 5 & 4 \\
\hline $\begin{array}{c}\text { Severe } \\
\text { (Asheman's) }\end{array}$ & 1 & 1.67 & 1 & 2.5 & 2 \\
\hline $\begin{array}{l}\text { Thick/irregular } \\
\text { endometrium }\end{array}$ & 10 & 16.67 & 5 & 12.5 & 15 \\
\hline Endometrial polyps & 5 & 8.33 & 2 & 5 & 7 \\
\hline Myoma & 1 & 1.67 & 1 & 2.5 & 2 \\
\hline Congenital abnormalities & 5 & 8.33 & 2 & 5 & 7 \\
\hline $\begin{array}{l}\text { Atrophic endometrium / } \\
\text { sclerotic ostia }\end{array}$ & 4 & 6.67 & 2 & 5 & 6 \\
\hline Foetal bones & 0 & 0 & 2 & 5 & 2 \\
\hline Normal Findings & 28 & 46.67 & 20 & 47.5 & 48 \\
\hline Test couldn't be done & 2 & 3.33 & 0 & 2 & 2 \\
\hline
\end{tabular}

Table-2 Distribution of cases according to laparoscopic findings

\begin{tabular}{|l|c|c|c|c|c|}
\hline Laparoscopic findings & $\begin{array}{c}\text { Primary } \\
\text { infertility } \\
\text { (N=60) }\end{array}$ & $\begin{array}{c}\text { Percentage } \\
\mathbf{( \% )}\end{array}$ & $\begin{array}{c}\text { Secondary } \\
\text { infertility } \\
\mathbf{( N = 4 0 )}\end{array}$ & $\begin{array}{c}\text { Percentage } \\
\mathbf{( \% )}\end{array}$ & $\begin{array}{c}\text { Total } \\
\text { No. of } \\
\text { cases. }\end{array}$ \\
\hline Adhesion & 8 & 13.33 & 5 & 12.5 & 13 \\
\hline$\bullet \quad$ Mild & 6 & 10 & 4 & 10 & 10 \\
\hline$\bullet \quad$ Moderate & 4 & 6.67 & 2 & 5 & 6 \\
\hline$\bullet \quad$ Severe & & & & & \\
\hline Endometriosis & 2 & 3.33 & 1 & 2.5 & 3 \\
\hline$\bullet \quad$ Mild & 0 & 0 & 0 & 0 & 0 \\
\hline$\bullet \quad$ Moderate & 1 & 1.67 & 0 & 0 & 1 \\
\hline \multicolumn{1}{|c|}{ Severe } & 15 & 25 & 4 & 10 & 19 \\
\hline Phimosis/hydrosalpinx & 22 & 36.67 & 4 & 10 & 26 \\
\hline $\begin{array}{l}\text { Polycystic / multicystic } \\
\text { ovaries }\end{array}$ & 6 & 10 & 2 & 5 & 8 \\
\hline Functional Ovarian Cyst & 1 & 1.67 & 2 & 5 & 3 \\
\hline Myoma & 7 & 11.67 & 3 & 7.5 & 10 \\
\hline Congenital abnormalities & 12 & 20 & 4 & 10 & 16 \\
\hline Tubo-ovarian masses & 20 & 33.33 & 12 & 30 & 32 \\
\hline Normal findings & & & & \\
\hline
\end{tabular}


Table-3 Distribution of cases according to treatment done byhysteroscopy

\begin{tabular}{|l|c|c|c|c|c|}
\hline Procedure & $\begin{array}{c}\text { Primary } \\
\text { infertility } \\
\text { (N=60) }\end{array}$ & $\begin{array}{c}\text { Percentage } \\
\mathbf{( \% )}\end{array}$ & $\begin{array}{c}\text { Secondary } \\
\text { infertility } \\
\text { (N=40) }\end{array}$ & $\begin{array}{c}\text { Percentage } \\
\text { (\%) }\end{array}$ & $\begin{array}{c}\text { Total No. } \\
\text { of cases }\end{array}$ \\
\hline Polypectomy & 5 & 8.33 & 2 & 5 & 7 \\
\hline Adhesiolysis & 4 & 6.67 & 4 & 10 & 8 \\
\hline Tubal cannulation & 4 & 6.67 & 2 & 5 & 6 \\
\hline Endometrial curettage & 12 & 20 & 5 & 12.5 & 17 \\
\hline No procedure done & 35 & 58.33 & 27 & 67.5 & 62 \\
\hline
\end{tabular}

Table-4 Distribution of cases according to treatment done by laparoscopy

\begin{tabular}{|l|c|c|c|c|c|}
\hline Procedure & $\begin{array}{c}\text { Primary } \\
\text { infertility } \\
(\mathbf{N = 6 0 )}\end{array}$ & $\begin{array}{c}\text { Percentage } \\
\mathbf{( \% )}\end{array}$ & $\begin{array}{c}\text { Secondary } \\
\text { infertility } \\
\mathbf{( N = 4 0 )}\end{array}$ & $\begin{array}{c}\text { Percentage } \\
\mathbf{( \% )}\end{array}$ & $\begin{array}{c}\text { Total } \\
\text { No. of } \\
\text { cases }\end{array}$ \\
\hline Adhesiolysis & 12 & 20 & 9 & 22.5 & 21 \\
\hline Laparoscopic ovarian drilling & 22 & 36.67 & 4 & 10 & 26 \\
\hline Fimbrioplasty & 12 & 20 & 3 & 7.5 & 15 \\
\hline $\begin{array}{l}\text { Fulguration of endometriotic } \\
\text { lesion }\end{array}$ & 2 & 3.33 & 1 & 2.5 & 3 \\
\hline $\begin{array}{l}\text { Excision of ovarian } \\
\text { endometriotic cyst }\end{array}$ & 1 & 1.67 & 0 & 0 & 1 \\
\hline Myomectomy & 1 & 1.67 & 2 & 5 & 3 \\
\hline No procedure done & 26 & 43.33 & 21 & 52.5 & 47 \\
\hline
\end{tabular}

Table-5 Pregnancy outcome in patients treated by laparohysteroscopy (observation period $=1$ year)

\begin{tabular}{|l|c|}
\hline Pregnancy Outcome & No. of Patients \\
\hline Conceived & 21 \\
\hline Not conceived & 44 \\
\hline Lost to follow up & 23 \\
\hline Referred for in vitro fertilization & 12 \\
\hline Total & 100 \\
\hline
\end{tabular}

\section{REFERENCES:}

1. World Health Organization.Manual for the standardized investigation and diagnosis of infertile couple.Cambridge, UK:Cambridge University Press 2000.

2. Jacky Boivin, Laura Bunting, John A Collins and Karl G. Nygren International estimates of infertility prevalence and tretment seeking, potential need and demand for infertility medical care. October 6, 2006. 
3. Brown SE, Coddington CC, Schnorr J,et al. Evaluation of outpatient hysteroscopy, saline infusion hysterosonography, and hysterosalpingography in infertile women, a prospective rrandomized study Fertil Steril 2000;74:1029-1034

4. Boudhraa K, Jelloul MA, Karsaoui O, Ben Aissia N, Overhamih, Triki A, Gara MF. Role of hysteroscopy and laparoscopy in management of the female infertility. Ternis media 2009 Jan; 87(1), 55-60.

5. Malhotra N, Sood M.Role of hysteroscopy in infertile women.Department of Obstetrics and Gynaecology, Lady Hardinge Medical College, New Delhi.J India Med Assoc. 1997,Sep;95(9):499,525.

6. Sajida Parveen, Madah Khanam, Star General Hospital. To find out the role of combined diagnostic laparoscopy and simultaneous diagnostic hysteroscopy for evaluation of female sub fertility factors. Journal of surgery Pakistan (International) 15(1) January-March 2010:44-46 